\title{
Age-related morphological peculiarities of human testes
}

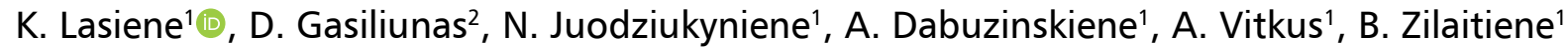 \\ ${ }^{1}$ Lithuanian University of Health Sciences, Kaunas, Lithuania \\ ${ }^{2}$ Kaunas Division of State Forensic Medicine Service
}

[Received: 12 February 2020; Accepted: 25 February 2020]

Background: This study aimed to compare the isolated testes size, volume, weight and density changes with age and to establish the suitability of three formulas of testicular volume calculation for 18-50 and 51-70-year-old men groups.

Materials and methods: Two hundred and six testes of 103 men (59 of 18-50-year-old and 44 of 51-70-year-old men) were weighed and their size was measured by the sliding calliper. The accurate volume was determined by water displacement and compared with volume calculated using three formulas, and the density of testicular tissues was calculated.

Results: The mean length and height of both testes and length and height of right and left testes decreased significantly with age. The mean width of both testes and width of right and left testes decreased with age insignificantly. The mean of water displacement volume and weight and volume and weight of right and left testes decreased with age significantly. The mean density of testicular tissues and the density of the right and left testes increased significantly with age. In the same age group, the size, water displacement volume and weight of right testes was insignificantly higher than that of the left ones, and the density of testicular tissues was similar in the right and left testes.

Conclusions: The prolate spheroid formula was most suitable for calculation of testicular volume for 18-50-year-old men and prolate ellipsoid formula was most suitable for calculation of testicular volume in 51-70-year-old men. (Folia Morphol 2021; 80, 1: 122-126)

Key words: density, men, size, testis, weight, volume

\section{INTRODUCTION}

Testicular function has a direct correlation with testicular volume. The seminiferous tubules and germinal elements comprise approximately $98 \%$ of testicular mass. Reduction in testicular size is mainly caused by reduction of these histological elements due to primary dysplasia or secondary damage and can therefore result in disturbed spermatogenesis $[3,14]$.

Mean size of testes had the significant correlation with total sperm count and sperm concentration, sperm motility, percentage of live sperm, sperm morphology and serum follicle-stimulating hormone, luteinizing hormone and testosterone levels. Therefore, the measuring of size of the testis can be helpful to assess rapidly andrological status during the initial physical examination [14].

Evaluation of morphological parameters of living men and male animals is complicated. Various methods can be used for the measurement of the testicular size for the living male patients in vivo. The size of testes can be evaluated using vernier calliper, ruler, 
orchidometer and ultrasound $[2,3,7,10,12,15]$. Using the evaluated parameters of testes size, testicular volume can be calculated using various formulas such as prolate ellipsoid formula, the formula for a prolate spheroid or the empiric formula of Lambert. Results of these formulas can be very different and controversial [5]. However, the isolated testes' water displacement, weighing and measurement are most rigorous methods for the evaluation of testicular volume, weight and size $[4,11,13]$.

The aim of this work was to compare changes of the morphological parameters (size, volume, weight and density) of isolated testes with age and establish the suitability of three formulas of testicular volume calculation for 18-50 and 51-70-year-old men groups.

\section{MATERIALS AND METHODS}

This work was approved by the Kaunas Region Biomedical Research Ethics Committee (No. BE-2-1, 07.04.2015 and No. P1-BE-2-2/2015, 08.07.2016).

Pairs of testes from the men aged 18-70 year were obtained from Kaunas Division of State Forensic Medicine Service after autopsy at least 24 hours "post mortem". The left testes were marked using the cotton thread. The material was placed into $10 \%$ formaldehyde solution for 24 hours. Two hundred and six testes of 103 men were used for this investigation. Men were divided into two age groups: 18-50-year-old $(n=59)$ and 51-70-year-old $(n=44)$. Only testes without visible morphological pathologies were selected as suitable for this investigation. The testes were rinsed in streaming tap water, dried with blotting paper and the remnants of epididymis, adipose tissue and ligaments were removed. Then the testes were weighed using KERN 440-21N balance. The length, width and height of each testis were measured using the sliding calliper. The accurate volume was measured by water displacement of each testis. All obtained data were tabled in the Microsoft Excel 2003 programme. Using this program, the volume of each testis was calculated using three formulas: (1) for a prolate ellipsoid: volume $=$ length $\times$ width $\times$ height $\times 0.52$; (2) for a prolate spheroid: volume $=$ length $\times$ width $^{2} \times 0.52$; and (3) the empiric formula of Lambert: volume $=$ length $\times$ width $\times$ height $\times 0.71[4,11,13]$.

Also, the density of testicular tissues was calculated for each testis using the formula: density = weight/ /water displacement volume.

\section{Statistical analysis}

The Statistica programme (Statistica Version 5, StatSoft Inc.) basic statistics was used for the calculation of the mean and standard deviation (SD). T-test for independent samples was used for statistical comparison of age groups ( $p$ values). Data were expressed as mean \pm standard deviation, and $p<0.05$ was taken as significant.

\section{RESULTS}

A mean size of the testes differed with age. The mean length of testes decreased significantly from $4.54 \pm 0.42 \mathrm{~cm}$ in $18-50$-year-old men to $4.17 \pm$ $\pm 0.49 \mathrm{~cm}$ in $51-70$-year-old men and their mean height decreased from $2.6 \pm 0.3 \mathrm{~cm}$ and $2.34 \pm 0.38 \mathrm{~cm}$ respectively $(p<0.05)$. Only the mean width decreased non-significantly with age (from $2.96 \pm 0.32 \mathrm{~cm}$ and $2.92 \pm 0.34 \mathrm{~cm}$ ). The size of the right and left testes of the 18-50-year-old group were higher than in 51-70-year-old men. The length and height of testes differed significantly $(p<0.05)$. Also, the size of right testes was insignificantly higher than that of left testes in the same age group men, but, in 51-70-year-old men group, the height was the same in the right and left testes ( $p>0.05$; Table 1).

The mean water displacement volume of both testes was significantly higher in 18-50-year-old men $(0.72 \pm 4.54 \mathrm{~mL})$ than in the $51-70$-year-old group $(16.88 \pm 4.67 \mathrm{~mL} ; p<0.05)$. The volume of right and left testes was higher in 18-50-year-old men in comparison with the volume of testes in 51-70-year-old men $(p<0.05)$. The volume of right testes was insignificantly higher than that of left testes in the same age group ( $p>0.05$; Fig. 1 ).

Comparing the water displacement volume with the results of the three testicular volume calculation formulas, contradictory results were obtained (Table 2). In 18-50-year-old men group, mean of both testes volume and volumes of right and left testes, which were calculated using prolate ellipsoid formula and empiric formula of Lambert, differed significantly from the water displacement volume $(p<0.05)$. Only results of prolate spheroid formula differed insignificantly from water displacement volume ( $p>0.05)$. In 51-70-year-old men group, the volumes calculated using prolate spheroid formula and empiric formula of Lambert, differed significantly from the water displacement volume $(p<0.05)$. Only results of prolate ellipsoid formula differed insignificantly from water displacement volume in the testes of this age group men 
Table 1. The length, width and height of the testes in 18-70-year-old men (mean \pm standard deviation)

\begin{tabular}{|c|c|c|c|c|}
\hline & Length [cm] & Width [cm] & Height [cm] & $\mathbf{P}$ \\
\hline \multicolumn{5}{|l|}{ Mean } \\
\hline 18-50-year-old & $4.54 \pm 0.42 \mathrm{a} 1$ & $2.96 \pm 0.32$ & $2.6 \pm 0.3 \mathrm{a} 3$ & a1:a2, a3:a4; $p<0.05$ \\
\hline 51-70-year-old & $4.17 \pm 0.49 \mathrm{a} 2$ & $2.92 \pm 0.34$ & $2.34 \pm 0.38 \mathrm{a} 4$ & \\
\hline \multicolumn{5}{|l|}{ Right } \\
\hline 18-50-year-old & $4.57 \pm 0.44 b 1$ & $2.98 \pm 0.31$ & $2.63 \pm 0.34 b 3$ & $b 1: b 2, b 3: b 4 ; p<0.05$ \\
\hline 51-70-year-old & $4.2 \pm 0.51$ b2 & $2.94 \pm 0.37$ & $2.34 \pm 0.37 b 4$ & \\
\hline \multicolumn{5}{|l|}{ Left } \\
\hline 18-50-year-old & $4.5 \pm 0.4 \mathrm{c} 1$ & $2.93 \pm 0.33$ & $2.58 \pm 0.25 c 3$ & 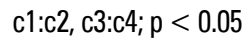 \\
\hline 51-70-year-old & $4.15 \pm 0.48 c 2$ & $2.9 \pm 0.32$ & $2.34 \pm 0.41 c 4$ & \\
\hline
\end{tabular}

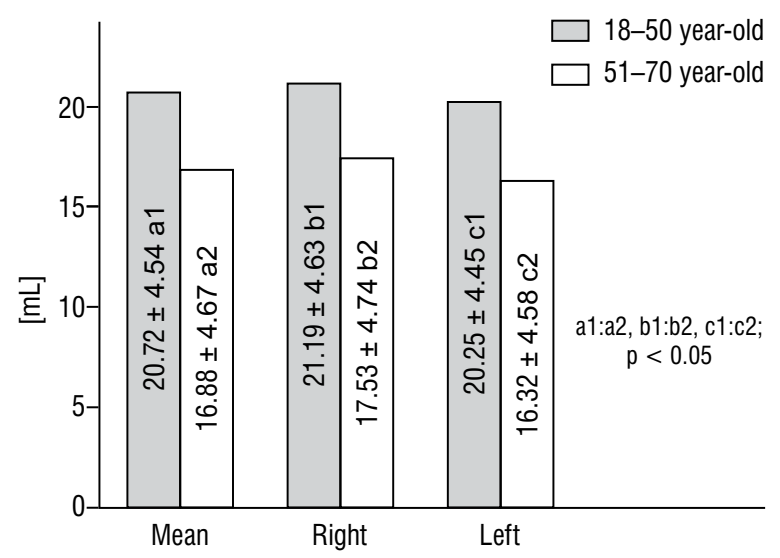

Figure 1. The water displacement volume of the testes in 18-70-year-old men (mean \pm standard deviation).
( $p>0.05)$. The obtained data showed that the Empiric formula of Lambert was completely unsuitable for the calculation of testicular volume in both age groups (the difference between results of water displacement and Empiric formula of Lambert was 20.69-25.98\%).

The mean weight of testes in 18-50-year-old men $(21.53 \pm 4.57 \mathrm{~g})$ was significantly higher than in the 51-70-year-old men $(17.91 \pm 5.01 \mathrm{~mL} ; \mathrm{p}<0.05)$. The weight of 18-50-year-old men right $(22.03 \pm 4.63 \mathrm{~g})$ and left $(21.03 \pm 4.5 \mathrm{~g})$ testes was higher than the weight of 51-70-year-old men testes $(21.03 \pm 4.5 \mathrm{~g}$ and $17.26 \pm 4.88 \mathrm{~g}$, respectively, $\mathrm{p}<0.05)$. The weight of right testes was higher than left testes in the same age men group ( $p>0.05 ;$ Fig. 2 ).

Table 2. The comparison of water displacement volume and volume calculated using three formulas in the 18-70-year-old men, $\mathrm{mL}$ (mean \pm standard deviation)

\begin{tabular}{|c|c|c|c|c|c|}
\hline & Water displacement & Prolate ellipsoid & Prolate spheroid & $\begin{array}{l}\text { Empiric formula } \\
\text { of Lambert }\end{array}$ & $\mathbf{P}$ \\
\hline \multicolumn{6}{|l|}{ Mean } \\
\hline 18-50-year-old & $20.72 \pm 4.54$ a1 & $18.36 \pm 4.4 \mathrm{a} 2$ & $21.0 \pm 5.45$ & $25.07 \pm 6.0 \mathrm{a} 3$ & a1:a2, a1:a3; $p<0.05$ \\
\hline $\begin{array}{l}\text { Difference with mean of water } \\
\text { displacement volume }\end{array}$ & - & $-2.36(11.39 \%)$ & $1.72(8.3 \%)$ & 4.35 (20.99\%) & \\
\hline 51-70-year-old & $16.88 \pm 4.67 \mathrm{~b} 1$ & $15.28 \pm 4.89$ & $19.06 \pm 5.69$ b2 & $20.87 \pm 6.67 \mathrm{~d} 3$ & $b 1: b 2, b 1: b 3 ; p<0.05$ \\
\hline $\begin{array}{l}\text { Difference with mean of water } \\
\text { displacement volume }\end{array}$ & - & $-1.6(9.48 \%)$ & $2.18(12.91 \%)$ & $3.99(23.64 \%)$ & \\
\hline \multicolumn{6}{|l|}{ Right } \\
\hline 18-50-year-old & $21.19 \pm 4.63 \mathrm{cl}$ & $18.85 \pm 4.69 \mathrm{c} 2$ & $21.46 \pm 5.5$ & $25.74 \pm 6.41 \mathrm{c3}$ & 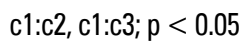 \\
\hline $\begin{array}{l}\text { Difference with mean of water } \\
\text { displacement volume }\end{array}$ & - & $-2.34(11.04 \%)$ & $0.27(1.27 \%)$ & $4.55(21.47 \%)$ & \\
\hline 51-70-year-old & $17.43 \pm 4.73 \mathrm{~d} 1$ & $15.51 \pm 5.08$ & $19.49 \pm 6.18 \mathrm{~d} 2$ & $21.17 \pm 6.93 \mathrm{~d} 3$ & $\mathrm{~d} 1: \mathrm{d} 2, \mathrm{~d} 1: \mathrm{d} 3 ; \mathrm{p}<0.05$ \\
\hline $\begin{array}{l}\text { Difference with mean of water } \\
\text { displacement volume }\end{array}$ & - & $-1.92(11.02 \%)$ & $2.06(11.82 \%)$ & $3.74(21.46 \%)$ & \\
\hline \multicolumn{6}{|l|}{ Left } \\
\hline 18-50-year-old & $20.25 \pm 4.45$ e1 & $17.87 \pm 4.06 \mathrm{e} 2$ & $20.54 \pm 5.44$ & $24.44 \pm 5.55$ e3 & e1:e2, e1:e3; $p<0.05$ \\
\hline $\begin{array}{l}\text { Difference with mean of water } \\
\text { displacement volume }\end{array}$ & - & $-2.38(11.75 \%)$ & $0.29(1.43 \%)$ & $4.19(20.69 \%)$ & \\
\hline 51-70-year-old & $16.32 \pm 4.58 \mathrm{f} 1$ & $15.06 \pm 4.74$ & $18.63 \pm 5.18$ f2 & $20.56 \pm 6.47$ f3 & $f 1:\{2, f 1: f 3 ; p<0.05$ \\
\hline $\begin{array}{l}\text { Difference with mean of water } \\
\text { displacement volume }\end{array}$ & - & $-1.26(7.72 \%)$ & $2.31(14.15 \%)$ & $4.24(25.98 \%)$ & \\
\hline
\end{tabular}




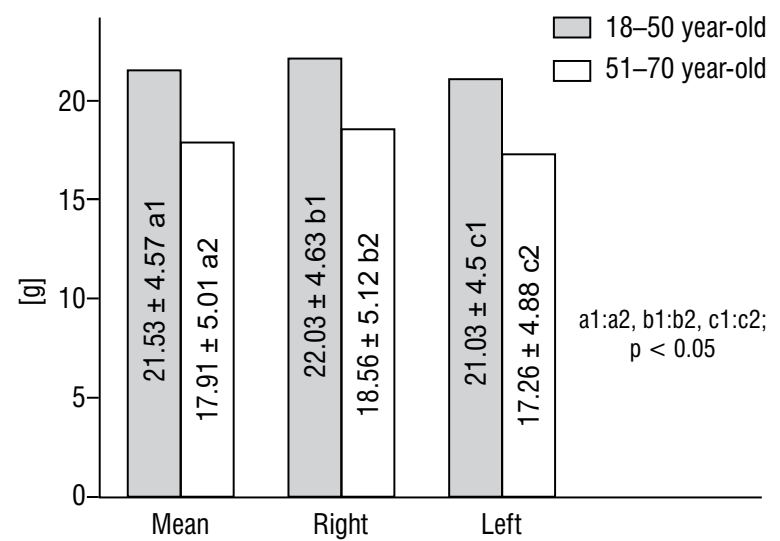

Figure 2. The testicular weight in 18-70-year-old men (mean \pm standard deviation).

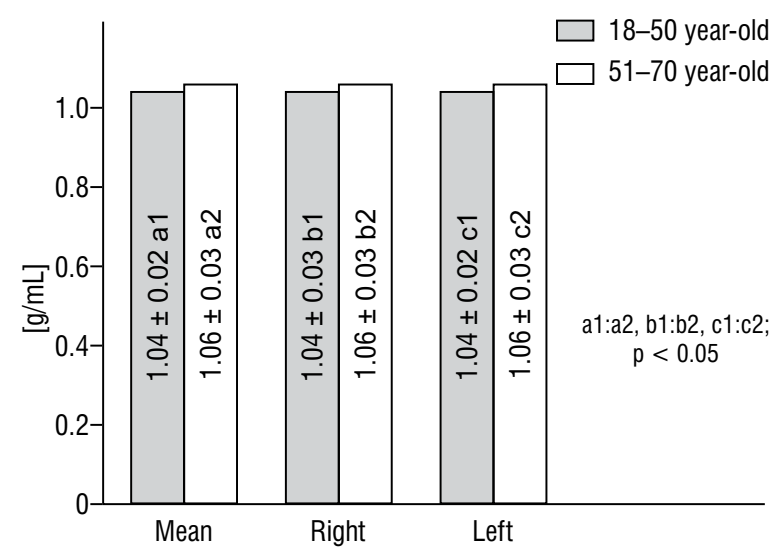

Figure 3. The density of testicular tissues in 18-70-year-old men (mean \pm standard deviation).

The mean density of testicular tissues was lower in 18-50-year-old men than in 51-70-year-old men $(1.04 \pm 0.02 \mathrm{~g} / \mathrm{mL}$ and $1.06 \pm 0.03 \mathrm{~g} / \mathrm{mL}$, respectively, $p<0.05)$. The tissue density of right $(1.04 \pm 0.03 \mathrm{~g} / \mathrm{mL})$ and left $(1.04 \pm 0.02 \mathrm{~g} / \mathrm{mL})$ testes was lower in 18-50-year-old men in comparison with the density of testicular tissues in 51-70-year-old men (1.06 \pm $\pm 0.03 \mathrm{~g} / \mathrm{L}$ and $1.06 \pm 0.03 \mathrm{~g}$, respectively, $\mathrm{p}<0.05$ ). In the same age group, the tissue density of the right and left testes was identical ( $p>0.05$; Fig. 3).

\section{DISCUSSION}

The male fecundity begins to decline in the late thirties, or in the forties. This decline may be the consequence of an associated decline in semen quality. Age-related decrease evidences in semen volume, total sperm count, motility and proportion of sperm with normal [1].

Kelvin et al. [8] measured the size of left and right testes of 18-64-year-old men and calculated their vol- ume. They estimated that the volume of right testes was lower than that of the left testes in patients aged $18-20$ and $41-50$ years. Also, the volume of right testes was higher in the patients of 51-64-year-old men group than in 18-50-year-old men. The volume of left testes was lower in the patients of 51-64-year-old group than in 41-50-year-old men [8]. Results of our investigation showed that the water displacement volume of the right testes was insignificantly higher than that of the left testes in the both investigated age groups. Also, the volume of right and left testes was significantly higher in 18-50-year-old men in comparison with 51-70-year-old men. Our results coincident with the results reported by Kothari and Gupta [9] and Tijani et al. [16] indicating that the volume of fertile men testes doesn't decline significantly with patient age.

Hsieh et al. [4], Mbaeri et al. [11] and Sakamoto et al. [13] compared volumes of patients' testes calculated using three formulas with water displacement volume. They estimated that the formula of Lambert is the optimal in clinical practice $[4,11,13]$. The results of our investigation contradict the proposition of these authors. Our obtained data show that the empiric formula of Lambert is completely unsuitable for the calculation of testicular volume. We ascertained that the prolate spheroid formula is most suitable for calculation of testes volume for 18-50-year-old men and prolate ellipsoid formula is most suitable for calculation of testes volume for 51-70-year-old men.

The density of testicular tissues varies with age. Johnson et al. [6] estimated that the testicular tunic weight increased, and the parenchyma weight decreased with age. Kothari and Gupta [9] predicated that ageing leads to a thickening of the tunica propria, inter-tubular fibrosis and progressive hyalinisation and atrophy of some tubules. The results of our investigation showed that mean density and density of testicular tissues of the left and right testes was significantly lower in 18-50-year-old men than in 51-70-year-old men. According to the data of the above-mentioned authors, the density of the tissues increases with age due to the proliferation of connective tissue and weight loss of parenchyma in the testes.

\section{CONCLUSIONS}

1. The mean size and the size of right and left testes decreased with age. The length and height decreased significantly. 
2. The water displacement volume's and weight's mean and the volume and weight of right and left testes decreased with age significantly.

3. The mean testicular tissues density and the density of the right and left testes increased significantly with age.

4. The prolate spheroid formula was most suitable for calculation of testicular volume for 18-50-year-old men and prolate ellipsoid formula was most suitable for calculation of testicular volume for 51-70-year-old men.

\section{Acknowledgements}

We would like to thank the technical staff of the Kaunas Division of State Forensic Medicine Service for their help in collecting material for our study.

\section{REFERENCES}

1. Auger J, Jouannet P. Age and male fertility: biological factors. Rev Epidemiol Sante Publique. 2005; 53 Spec No 2: 2S25-35, indexed in Pubmed: 16471142.

2. Cha M, Ahn B, Kim Y. Inaccuracy in Ultrasonographic Measurement of the Testicular Volume in Children. Korean J Urol. 2006; 47(8): 866, doi: 10.4111/ kju.2006.47.8.866.

3. Goede J, Hack WWM, Sijstermans K, et al. Normative values for testicular volume measured by ultrasonography in a normal population from infancy to adolescence. Horm Res Paediatr. 2011; 76(1): 56-64, doi: 10.1159/000326057, indexed in Pubmed: 21464560.

4. Hsieh ML, Huang ST, Huang HC, et al. The reliability of ultrasonographic measurements for testicular volume assessment: comparison of three common formulas with true testicular volume. Asian J Androl. 2009; 11(2): 261-265, doi: 10.1038/aja.2008.48, indexed in Pubmed: 19151736.

5. Innocent M, Asomugha L, Ukamaka M, et al. Ultrasound measured testicular volume in Nigerian adults: Relationship of the three formulae with height, body weight, body-surface area, and body-mass index. Int J Adv Med Health Res. 2016; 3(2): 85, doi: 10.4103/2349-4220.195940.

6. Johnson L, Petty CS, Neaves WB. Influence of age on sperm production and testicular weights in men. J Reprod
Fertil. 1984; 70(1): 211-218, doi: 10.1530/jrf.0.0700211, indexed in Pubmed: 6694139.

7. Karaman MI, Kaya C, Caskurlu T, et al. Measurement of pediatric testicular volume with Prader orchidometer: comparison of different hands. Pediatr Surg Int. 2005; 21(7): 517-520, doi: 10.1007/s00383-005-1470-1, indexed in Pubmed: 16010550.

8. Kelvin KE, Chukwuemeka NN, Adeyanju AR, et al. UItrasound measurement of testicular volume in healthy nigerian adults. J Asian Sci Res. 2012; 2(2): 45-52.

9. Kothari LK, Gupta AS. Effect of ageing on the volume, structure and total Leydig cell content of the human testis. Int J Fertil. 1974; 19(3): 140-146, indexed in Pubmed: 4375123.

10. Mbaeri TU, Orakwe JC, Nwofor AM, et al. Accuracy of Prader orchidometer in measuring testicular volume. Niger J Clin Pract. 2013; 16(3): 348-351, doi: 10.4103/11193077.113460, indexed in Pubmed: 23771459.

11. Mbaeri TU, Orakwe JC, Nwofor A, et al. Ultrasound measurements of testicular volume: Comparing the three common formulas with the true testicular volume determined by water displacement. Afr J Urol. 2013; 19(2): 69-73, doi: 10.1016/j.afju.2012.11.004.

12. Sakamoto H, Ogawa Y, Yoshida H. Relationship between testicular volume and testicular function: comparison of the Prader orchidometric and ultrasonographic measurements in patients with infertility. Asian J Androl. 2008; 10(2): 319-324, doi: 10.1111/j.1745-7262.2008.00340.x, indexed in Pubmed: 18097521.

13. Sakamoto H, Saito K, Oohta M, et al. Testicular volume measurement: comparison of ultrasonography, orchidometry, and water displacement. Urology. 2007; 69(1): 152-157, doi: 10.1016/j.urology.2006.09.012, indexed in Pubmed: 17270639.

14. Takihara H, Cosentino MJ, Sakatoku J, et al. Significance of testicular size measurement in andrology: II. Correlation of testicular size with testicular function. J Urol. 1987; 137(3): 416-419, doi: 10.1016/s0022-5347(17)44053-5, indexed in Pubmed: 3102757.

15. Taskinen S, Taavitsainen M, Wikström S. Measurement of testicular volume: comparison of 3 different methods. J Urol. 1996; 155(3): 930-933, indexed in Pubmed: 8583610.

16. Tijani KH, Oyende BO, Awosanya GO, et al. Assessment of testicular volume: A comparison of fertile and sub-fertile West African men. Afr J Urol. 2014; 20(3): 136-140, doi: 10.1016/j.afju.2014.05.001. 